This is the authors' accepted version of the manuscript.

Willis, R., Pathak, P., Khambhaita, P. \& Evandrou, M. (2016) ‘Complexities of cultural difference in social care work in England', European Journal of Social Work, Online

first. http://dx.doi.org/10.1080/13691457.2016.1255597

\title{
Complexities of cultural difference in social care work in England
}

Rosalind Willis ${ }^{1}$

Pathik Pathak ${ }^{2}$

Priya Khambhaita ${ }^{3}$

Maria Evandrou ${ }^{1}$

${ }^{1}$ Centre for Research on Ageing, Social Sciences, University of Southampton, Highfield, Southampton, SO17 1BJ

${ }^{2}$ Department of Sociology, Social Policy \& Criminology, Social Sciences, University of Southampton, Highfield, Southampton, SO17 1BJ

${ }^{3}$ Faculty of Health Sciences, University of Southampton, Highfield, Southampton, SO17 1BJ

r.m.willis@soton.ac.uk

p.pathak@soton.ac.uk

pk105@soton.ac.uk

maria.evandrou@soton.ac.uk 


\section{Corresponding author:}

Dr Rosalind Willis

Centre for Research on Ageing

Social Sciences

University of Southampton

Highfield

Southampton

SO17 1BJ

r.m.willis@soton.ac.uk

+44 (0)2380595367

\section{Funding information}

This paper presents independent research funded by the National Institute for Health Research (NIHR) School for Social Care Research (SSCR), grant number T976 T11-017 USRW. The views expressed are those of the authors and not necessarily those of the SSCR, the NHS, the NIHR or the Department of Health.

\section{Acknowledgements}

We would like to thank the participants who volunteered their time and shared their experiences with us. We would also like to thank all the members of the advisory panel for their guidance, and the social services staff and members of the community who helped us to carry out this project.

\section{Statement of conflict of interest}

No conflicts of interest. 


\title{
Complexities of cultural difference in social care work in England
}

\begin{abstract}
The ageing of the ethnic minority population in Britain has led to a more ethnically diverse older client group for social care services than has ever been the case. This article focuses on the issue of how social care staff in England experience working across differences of culture, ethnicity, religion, and language. First, the article critically discusses the concept of cultural competence. Then, it reports on the perspectives of social care staff on their attempts to work in a culturally competent way. Individual in-depth qualitative interviews were carried out with 39 social care practitioners, and thematically analysed. Themes related to professional competence, appropriate behaviour, and training needs. Some practitioners felt unable to perform to their accustomed skill level when working across diversity, which has implications for the quality of care provided and job satisfaction. Other practitioners were confident in working across diversity. The key difference between these practitioners was a degree of cultural reflexivity. Recommendations for training are provided.
\end{abstract}

Keywords: cultural competence; staff development; ethnicity; culture; diversity 


\section{Introduction}

This paper focuses on how social care staff in England experience working across differences of culture, ethnicity, religion, and language. It reports on the perspectives of social care staff on how to work in a culturally and professionally competent way, and explores their level of comfort when working with difference, and the extent to which they perceive the existing training on cultural competence meets their needs.

\section{Cultural competence}

There is disagreement in the literature about how to define cultural competence in health and social care (Gunaratnam, 2007; Williams \& Parrott, 2013). Goldberg (2000) argues that cultural competence includes both receiving and producing behaviour; that is being able to understand social cues (receive) and to behave in socially appropriate ways (produce) for a particular culture. On the other hand, Basham (2004) lists nine standards for cultural competence at the individual and organisational levels, which include knowledge of particular cultural beliefs and behaviours, awareness of one's own cultural practices and inherent biases, and the service employing staff from diverse backgrounds. The concept of cultural competence was broken down into three components by Gunaratnam (2007), namely cultural sensitivity, cultural knowledge, and cultural skills. Cultural sensitivity involves having respect for cultures other than one's own; cultural knowledge involves factual information about a culture's beliefs and behaviours; and cultural skills implies an ability to apply the two previous aspects to professional work. Mlcek (2014) adds a need for an awareness of historical and structural factors leading to social inequalities. The concept of cultural competence has been expanded to refer not only to ethnic minorities, but also minorities in terms of sexuality, disability, or socio-economic status (Harrison \& Turner, 2011; Jack \& Gill, 2013).

The changing makeup of Britain's population in the last few decades, in particular the ageing of the ethnic minority population (Lievesley, 2010), has made equality in health and social care a 
policy imperative (DH, 2001; HMG, 2010). Cultural competence is necessary because social care has been described as Eurocentric or Western in orientation (Williams \& Soydan, 2005; Yan, 2008), implying that social care is founded on individualistic values. Such values are culturally specific, and may not be perceived as appropriate by somebody from a collectivist culture, for example (Yan, 2008).

Although recognising that cultural competence is important, the concept has been criticised (Gunaratnam, 2007; Yu, 2009). Yu (2009) identifies two false assumptions implicit in cultural competence: first, that the way in which people interact with social care is inevitably shaped by their culture; and second, that all members of a group conform to the same cultural practices with the same intensity. The first assumption prioritises culture as the foremost aspect of an individual's life, instead of allowing the possibility for culture to be wielded to a greater or lesser degree depending on the situation. The second assumption is a form of 'othering' (Harrison \& Turner, 2011). That is, it views people from a different group as all sharing the same characteristics, rather than recognising that people can choose to follow some cultural practices but not others (Richardson, Thomas \& Richardson, 2006). A rigid focus on 'cultural' beliefs and behaviours can actually be the opposite of a person-centred approach. It ignores the agency of the client, and ignores the possibility that clients socially construct their individual identity.

A further critique of cultural competence is that it tends to prioritise membership of an ethnic group over other aspects of a person's identity, e.g. their gender, social class, or sexuality (Johnson \& Munch, 2009). All of these multiple identities may have a bearing on the reason a person is using social care services, and ought to be engaged with by the practitioner. However, the focus on cultural competence tends to minimise other identities, and the fact that a client is a woman may be lost in the fact that she is also Taiwanese, for example. This is reductionism; the tendency to attribute the reason for any behaviour of a minority ethnic client to culture rather than any other reason (Williams \& Soydan, 2005). 
Some practitioners have argued that viewing minority ethnic clients as requiring different kinds of care is in itself racist, and that everyone should be treated equally; through a colour-blind approach (Thomas \& Dines, 1994; Mlcek, 2014). However, the colour-blind approach is insupportable because the attempt to treat all clients as 'the same' is actually a veiled attempt to treat all clients as 'white' (Proctor \& Davis, 1994). It also means that staff cannot talk about, or ask about, ethnicity or discrimination with the client. Therefore, it fails to recognise the impact of being part of a minority group on a person's life and circumstances.

\section{Training}

It is in the face of such tensions that diversity training is provided. Training for health and social care staff on issues of ethnicity, culture, religion, etc, tends to take one of two forms: a focus on respecting difference and recognition of one's own biases (awareness training); and training on specific cultural or religious practices of individual groups (factfile training) (Gunaratnam, 1997). Factfile approaches tend to provide lists of festivals, celebrations, foods, and beliefs that are associated with specific groups. On the other hand, the awareness training tends to focus on an exploration of the beliefs and assumptions of the practitioners, and respect for different ways of thinking and behaviour (Loya, 2011). Past studies have shown that some practitioners prefer the factfile approach because it can provide specialised training in how to work most appropriately with the minority groups in their area (Bowes \& Dar, 2000). The factfiles are attractive to staff, because they reduce their uncertainties about cultural difference (Gunaratnam, 1997). Several authors have cautioned that the use of such guidelines without an accompanying person-centred approach would lead to stereotyping (Murphy \& Macleod Clarke, 1993; Thomas \& Dines, 1994). Since ethnic identity and religious and cultural practices are fluid and change over time, the factfile is essentially out-ofdate as soon as it is written (Gunaratnam, 1997). Bowes and Dar (2000) recommend that factfile approaches should only be provided alongside training on how to challenge discrimination, and a regular review and consultation with minority ethnic communities to ensure the factfile is relevant. 
Others have championed awareness training, advocating that practitioners must examine, and learn to overcome, their own assumptions and prejudices (Johnson \& Munch, 2009). Despite the advocates, there is little evidence for the effectiveness of cultural competency training (Harrison \& Turner, 2011).

\section{Anxieties and tensions}

Despite having access to some forms of training on working with diverse clients, the literature demonstrates that white practitioners still experience anxieties with this work. For example, social workers in Bowes and Dar's study (2000) had received 'anti-racist' training from the Local Authority. However, the practitioners were concerned that they did not have the specialised knowledge of the cultures they were working with (Pakistani older people in Scotland), and they reported that the training had only raised their anxiety levels that they might behave in culturally inappropriate ways with their clients (Bowes \& Dar, 2000). In a study of hospice work, staff discussed their fears that they would offend their clients and families at a sensitive time (Gunaratnam, 1997). They were also afraid that they would be viewed as racist if they asked questions about culturally specific practices, recalling the colour-blind approach. Social work students in Australia reported feeling intimidated by issues of race, and fearful of unintentionally offending clients (Mlcek, 2014). Proctor and Davies (1994) discuss a fear on the part of social workers that admitting a lack of cultural knowledge would make them appear professionally incompetent. On the contrary, some authors argue that admitting a lack of knowledge of a client's cultural practices can actually facilitate rapport, a vital part of the practitioner's toolkit (Johnson \& Munch, 2009; Harrison \& Turner, 2011). The practitioner must be willing to surrender some of their status and admit that they do not hold all of the knowledge in the relationship, which can be difficult because it undermines their sense of professional competence (Gunaratnam, 2007).

\section{Language}


Additional difficulties in providing a health or social care service arise when practitioners do not share a language with the client (Chand, 2005; Richardson et al., 2006). Difficulties of such work include a concern that interpreters do not translate the practitioner's full message (Richardson et al., 2006), and the inappropriateness of relying on family members as interpreters (Chand, 2005). Language barriers can result in clients feeling vulnerable, as in the case of a study of UK hospital patients (Ellins \& Glasby, 2016). However, the literature shows that practitioners also find language barriers challenging, for example a UK study of nursing care found that nurses believed they were unable to provide the "total patient care" that they would normally provide, because they could not discuss it with patients (Murphy \& Macleod Clarke, 1993: 448). These communication barriers inhibited the nurses' normal work practice of encouraging the clients to become more independent and to take on some of their own care. Such discussions and negotiations around independence are also central to social care work (Staples, 2000; Yan, 2008; Williams \& Parrott, 2013).

\section{Methodology}

These data form part of a larger project (Willis, Khambhaita, Pathak \& Evandrou, 2015), with the aim to understand ethnic group differences in social care satisfaction (HSCIC, 2013). Interviews were conducted with service users, family carers, and practitioners from different ethnic groups. This paper reports on the practitioner interviews.

Thirty-nine adult social services practitioners were interviewed. These 39 practitioners included people who worked for Local Authority adult social services, private personal care companies subcontracted from the Local Authority, and the voluntary sector. The job roles of the participants included social worker, occupational therapist, domiciliary carer, care home carer, day care assistant, manager, commissioner, and volunteer. Practitioners worked with a range of clients, including older people with physical disabilities or dementia, and working-age clients with disabilities. The participants were from different ethnic backgrounds, reflecting the composition of the social care workforce. The majority were White British (25), followed by Asian (6), 'Other' White (5), Black 
African (2), and Filipino (1). Thirteen of the practitioners were male, and 26 were female. In the anonymised quotations below, the practitioners are identified with an ID number (e.g. P01 means practitioner number 1) and their ethnicity and job role.

A combination of purposive, convenience, and snowball sampling was carried out to select the practitioners (Bryman, 2012). Only those from adult social services or allied charity services were eligible. Participants were recruited through placing advertisements on email lists and physical notice boards at three Local Authorities in the South of England. Additional participants were recruited through word-of-mouth, and some serendipitously at recruitment events for service users.

Individual in-depth interviews were carried out with each practitioner in a convenient location, e.g. their workplace or the University. The goals of the interviews were to understand their typical work routine, their experiences of diversity at work, and to gain their reflections on minority clients' satisfaction. It should be noted that the interview topic guides did not contain a question specifically about professional or cultural competence, and so the findings here arose spontaneously in the interviews with some, but not all, participants. It is of interest that the discussions of how professional competence is challenged by diversity mostly arose in the White British interviews. All participants gave informed consent to the interview. Ethical approval for the study was obtained from the national Social Care Research Ethics Committee, and research governance approval was obtained from the three Local Authorities.

The interviews were audio recorded and transcribed. They were analysed using thematic analysis, using open coding and constant comparison (Braun \& Clarke, 2006). Data were organised using the NVivo 10 software, which has useful categorising and search facilities suitable for thematic analysis. Transcripts were analysed with a view to answering the main research question, which has been answered elsewhere (Willis et al., 2015). As is usual in thematic analysis, themes emerge from the data that go beyond the original research question, and some of these themes form the basis of this article. 


\section{Findings}

The various themes presented below are reflections of some practitioners' feelings of being underskilled to work with diverse client groups.

\section{Diversity as a challenge to professional competence}

Within the practitioners' discussions of their job roles, the importance of enhancing independence, choice, and control was emphasised. The practitioners' work was shaped by an ideology whereby clients are enabled to become as independent as possible with the help of the services. The following two quotations refer to the nature of social care work in general, rather than working with Black and Minority Ethnic (BME) clients specifically.

We support independence. The less we have to do for a person, the better it is ... and in fact, the less I do, the more of a success I consider it. (P32, White British, Manager)

Within this ideology, practitioners encouraged clients to work with them in order to reach a position where the client is in control of their care. The care is personalised, meaning that it is adapted to meet the individual needs of each client rather than a one-size-fits-all approach. Reaching this point of client-controlled care is not a straightforward process. Many practitioners discussed a process of negotiation, where the practitioner encourages the client to gradually adjust their expectations. This takes time and skill.

And I think that is, again, something when you go in to see people, particularly on their first couple of visits where you're talking to them and you're saying, 'Well, what would you like?' 'Well dear, what's going to be easiest for you?' 'No, this is about you; this is about what you want.' You know, and you have to work quite hard to get out their needs from them, they just want to make it as easy for you as possible and it shouldn't be like that. And it's getting them to think a little bit differently when you're there. (P09, White British, Domiciliary Care Worker) 
Now, we turn to the challenges experienced by social care workers when attempting to apply these principles to work with minority ethnic clients. Clearly, the negotiation process requires good communication. Language is fundamental to that communication, and many practitioners discussed the difficulties they face when they do not speak the same language as their clients. Some practitioners said language barriers made their work impossible, because they wield language as a tool to achieve their professional goals.

The major part of this job role, I feel, is communication and if there's a breakdown in that link then the whole work doesn't happen. (P20, White British, Manager)

In some cases language barriers are overcome by interpreters, but this is not always sufficient to enable the practitioner to work to their full skill level. One gave an example of a situation where she was not able to convey her advice properly to the client and his wife (his family carer), because the client was translating for his wife. The practitioner was unable to employ her usual negotiating skills and, as a result, was not able to discuss how best to support the carer, who in the practitioner's opinion was providing too much help for her husband.

One of the clients I have seen, his wife was extremely supportive in fact a bit too supportive I would have said in that she was physically helping him do a lot and whereas I was trying to encourage his independence, I wasn't very successful because she spoke practically no English and it was down to him to translate and I don't know what was being translated ... But of course I couldn't effectively communicate with his wife as a carer ... but I don't really think they were taking on board what I was saying in terms of advice. (P06, White British, Occupational Therapist)

Language is not the only barrier to clear communication. Many practitioners felt that they were unable to employ their professional skills to their usual levels when there was a cultural difference between themselves and the clients. They reported that their lack of understanding of the clients' 
lifestyle meant they couldn't successfully work with the client. This cultural distance can lead to practitioners misunderstanding the client's needs, and a failure to provide personalised care.

Communication, probably makes it a lot easier ... if I'm assessing somebody who's of the same ethnic background I don't have to then consider the differences in my culture to theirs and obviously the language, so that probably would make it easier for me. So, yeah, when I'm assessing somebody of not my ethnic background, yeah, there's definitely more to my assessment. I think there's a lot of culture that goes into people's, how they choose to live in their own homes ... So yes, it does make a difference, yeah, it's easier. (P07, White British, Occupational Therapist)

Next, a manager reflects on their staff members' abilities to work across diversity. The staff members' lack of knowledge is thought to lead to 'great difficulty' in the work because they won't be able to meet the client's needs, and therefore the care provided will not be 'effective'. Cultural differences are presented as a challenge to successful care.

Yeah. I think in terms of sharing the concerns about our lack of awareness and knowledge of other cultures and backgrounds to a degree where we can provide an effective service would probably be shared by other colleagues - certainly the colleagues that have dealt with those cases in the past, I can imagine would experience great difficulty in trying to meet the service users' needs but find it difficult because of that lack of awareness or knowledge or in-depth background. (P26, White British, Manager)

So far, the focus has been on how practitioners felt that differences can limit their ability to employ their usual professional repertoire. However, there were also examples of practitioners' awareness that they need to work differently with minority clients, but they did not always feel equipped to do so. 
The White British practitioners' concerns about working with clients from minority ethnic groups included uncertainty about culturally appropriate behaviour, and a fear of appearing ignorant of such behaviours. One of the practitioner's main concern was uncertainty about how best to behave in the client's house. For example, she understood that in some cultures it is appropriate to take one's shoes off upon entering the house. However, she did not know exactly which cultures this social norm related to. Furthermore, she did not know whether it was polite to ask if she should take her shoes off, or if the client would be unhappy that she did not already know. Her desired solution was to receive training so she could be confident about these sorts of cultural expectations, and show that she was knowledgeable about the client's culture and hence build rapport.

I personally would feel that if there was something specifically that was a course on Islam ... and about what their needs are and their expectations of people coming into their house ... that that would help, and I feel like if I had that knowledge I could be a bit more respectful in advance, rather than having to find out as we go along and they say something, you know, 'Well could you?' [take your shoes off] Which kind of makes you think, 'Oh gosh, I probably should have known that first,' because I think that would help with the rapport building. (P06, White British, Occupational Therapist)

An Asian residential care worker discussed how her implicit understanding of her Asian residents' hygiene preferences made her more competent than her British colleagues to help these clients. However, she had been just as confused as the participant quoted above when it came to the White British residents' needs.

I think like we know a bit better about Asian residents. What they would need, like White British they didn't need showers most of them they didn't need shower or bath every day. But if there's Asian, they mostly yeah they do need shower in the morning. So we [Asian care workers] know about that... I got a colleague whose British, they might not understand that, why Asian residents want to shower everyday, the basic reason behind it or if there is any 
other need. I mean ... when I started work ... I didn't understand why don't they [White British residents] have shower everyday? We do! (P12, Asian, Care Worker).

There were two themes that arose in the interviews of BME practitioners that did not appear in the White British transcripts. These were a cultural motivation for care work, and experiences of discrimination. Three practitioners, from Asian, Filipino, and Black African backgrounds, drew on a perceived cultural value of the importance of caring for the older generation as their motivation for a career in care work. They distinguished their cultures from British culture here, with the implicit assumption that it is not shared. There is also an implication that such values enhance professional competence.

Being Asian, Indian, we have joint families, respect for our elders, elderly parents, I know how to deal with the client, take care of them. It is in our blood. It wasn't hard for me. (P36, Asian, Care Worker).

Some of the BME practitioners had experienced discrimination due to their ethnicity. A Filipino practitioner said that they had experienced resentment from white staff in a more junior position. A Black African practitioner reported that some white clients had specifically said that they did not want him to be their care worker. Although this was openly stated on three occasions, there was also an unspoken sense of discrimination in other care encounters.

I think there is a common, silent understanding between care staff and clients that people are treated differently according to their colour. It is like racial discrimination but in a silent way. Everyone can feel it, all carers can feel it. (P02, Black African, Care Worker)

Such discrimination cannot fail to undermine one's sense of professional competence.

\section{Potential solutions - Asking the right questions}


The idea of it being inappropriate to ask questions about a client's culture or religion appeared in many of the interviews. Some practitioners believed that it would be insensitive or offensive to ask such questions. The degree to which this is a problem for some practitioners is vividly evoked by the emotional language used: 'fear', 'frightened', and 'worried'. These emotions can lead practitioners to lose confidence that they have the professional competence to work with diverse clients.

I know you shouldn't ask somebody to explain their culture to you because you can do that research yourself but what you're asking is what, what is important to the person about the way they live their life and that I think is the bit that people [practitioners] are frightened to do so they're too worried about how they approach somebody and how they communicate with somebody so then they don't ask the right questions so they then come back with half the story ... Sometimes it's about, it's a lack of confidence in their own ability. (P01, White British, Social Worker)

However, they also realised that not asking the right questions, especially at the assessment stage, would result in somebody's needs not being fully met. Many practitioners were not able to resolve this dilemma. Some felt paralysed by the uncertainty about how best to proceed. By contrast, in other interviews diversity was not presented as problematic; this practitioner reported that the care plan explicitly includes how specific personal care needs should be met for each client.

It's about actually putting across the diversity and the dignity of the client, and ... you do a risk assessment and you do a care plan, so all carers work to that care plan. So if they are not able to eat meat or they are not able to do something or they are not able to fully undress, then that will be put into the care plan. (P17, White British, Manager)

Another practitioner said that he is aware that it is possible to unintentionally offend clients, but he copes by trying not to dwell on that fear. This shows the importance of not being afraid to ask the right questions during assessment. 
I try and deal with people very straightforwardly and I try not to get too caught up in the fact that I might do something wrong in some way, which I know is awkward for people, but I try and just sort of ask them the same questions in the same way. (P32, White British, Manager)

\section{Potential solutions - The 'right' kind of training}

There was a split in opinions as to how training for working with diverse clients should be designed. Many White British practitioners said that the current training was insufficient. They described the existing diversity training, which emphasises respect of differences, but the usefulness of the training was questioned.

I remember this year I [attended] an ethnic minority training day ... and what I found was the outcome of that training day, there was nothing that was special or unique, does that make sense, of what they were teaching about how to, you know, respond to the needs of some ethnic minority groups, actually I felt it was everybody and anybody of any generation. (P07, White British, Occupational Therapist)

Several White British practitioners said that they wished to have training on specific cultural practices, including information about expectations when visiting somebody from a particular culture or religion, e.g. rituals around washing, food preparation, religious festivals, and prayer timings. They said that such training would be best delivered by representatives from each of the relevant religious, cultural, or ethnic backgrounds. They did not want to be taught about different cultures by a White British trainer.

It isn't just about sitting in a classroom and telling people, a group of people, about recognising and identifying and dignity and respect. It needs more than that. There should be something in place where ... bring somebody in from one of the backgrounds ... let's do something around it. That's not happening. (P30, White British, Activity Co-Ordinator) 
In contrast, one of the Asian practitioners cautioned that training on specific group behaviours would result in stereotyping those groups. Instead, it was argued that the training should be more about understanding one's own assumptions and prejudices. Some White British practitioners agreed with this perspective.

It shouldn't be something like 'Muslims do this, Sikhs do that' you end up stereotyping groups by doing that. The training should be caring, person-centred, with an awareness of your own prejudices. (P22, Asian, Housing)

The key to culturally competent assessment was described as an awareness of the impact of different characteristics on both the client and the practitioner, and therefore on the assessment process itself. Here it is shown that reflexivity about one's own ethno-cultural perspective is central.

Well, if a social worker goes out, they have a heightened awareness of the impact of race, in my view, of the impact of race and language on their assessment and they can conduct open and effective assessment. They don't have to share the ethnicity of the person that they're assessing ... but unless there's an awareness and a heightened awareness of that then the assessment is going to be flawed, I think. (P05, White British, Manager)

\section{Potential solutions - Need to be even more person-centred with minority clients}

Person-centred care was presented as the goal of all social care work, and in some cases incorporating cultural or religious differences was described as the same as a person-centred process. However, some practitioners took this further and argued that they need to have an even greater emphasis on person-centred care with minority clients. Here, the practitioner discusses how sharing knowledge within their team leads to better person-centred care.

Well we also often have conversations about other cultures and about how the ethnic minorities lead, or needs, and very often we find that we lack knowledge so it's interesting to hear and to speak between ourselves about when we get cases and we need to be a bit 
more person-centred in the way that we put a support plan together and we commission the services and we speak with care providers about how they can meet those needs. (P15, 'Other' White, Social Worker)

Because we know there isn't a vast amount of services out there that have people with the skills to communicate effectively, we'd probably look at things in a much more personcentred way with the BME community to ensure that we identify what those individual people need and how we can help to deliver it. (P39, White British, Commissioner)

This may be the key for social care practitioners to work competently with clients from different backgrounds to themselves; utilising the familiar concept of person-centred care and asking questions may allow them to reclaim their sense of professional competence.

\section{Discussion}

This paper set out to understand the experiences of social care practitioners from three Local Authority areas in the South of England working with issues of diversity. The interconnected themes found in the transcripts related to professional competence, uncertainties about how to behave, and training needs.

Some practitioners felt unable to perform to their accustomed skill level when working across differences, citing the core principles of choice and control. Practitioners discussed the negotiation process they go through with clients, encouraging them to utilise social care services to become as independent as possible. The practitioners in the present study viewed this as the goal of good social care work. However, the negotiation process involves clear communication and conversations between the practitioner and the client and informal carer. This clear communication is inhibited at the most basic level by language barriers, and working through official interpreters does not eliminate the barrier (Richardson et al., 2006). Even when client and practitioner speak the same language, some practitioners discussed how the client's culture might be a barrier to the 
client's acceptance of enablement. Practitioners felt unable to work effectively when they faced these communication barriers. Similar findings were reported by Murphy and Macleod Clark (1993) in their study of nurses, which is now over 20 years old, and more recently (Ellins \& Glasby, 2016), indicating the continued difficulty of solving these communication issues. Some participants in the present study resolved the problem by pursuing the negotiation, and working through the interpreter to raise the questions they would raise with an English-speaking client about enablement. This must require a certain degree of perseverance.

The perceived shortcomings of the existing training led to uncertainty about how to behave with clients from different backgrounds. Thus, these practitioners understood cultural competence to be similar to Goldberg's (2000) definition, that of being able to both produce and receive culturally appropriate behaviours. Several practitioners believed that the existing training would be enhanced with the inclusion of a factfile approach (Gunaratnam, 1997), but only if these 'facts' were shared and discussed by somebody from the relevant minority groups, bestowing legitimacy. Factfile approaches have been strongly criticised in the literature (Yu, 2009). It is important not to view factfile training as complete and comprehensive simply because a person from a minority group delivers it, rather than a person from a white majority background. Any training would need to contain a critical element, raising the awareness of the fluid and individual nature of culture (Bowes \& Dar, 2000; Mlcek, 2014).

Uncertainties about how to behave with clients from different backgrounds included the dilemma about whether admitting ignorance would result in improved or worsened rapport. As seen from the past literature, there is a strong argument that if social care practitioners relinquish their expert position to ask diverse clients to educate them about their different needs, they can develop a good rapport with clients (Proctor \& Davis, 1994; Johnson \& Munch, 2009; Harrison \& Turner, 2011). The fact that some of the practitioners in the present study were unsure about the best practice in the face of this dilemma indicates that the training they receive on diversity does not 
address this question. Some of the practitioners interviewed for the present study agreed that it is important to feel comfortable asking questions about diverse needs. The fear of asking such questions derived from a feeling that it was politically incorrect to draw attention to difference by asking about it. The result of not asking questions is that practitioners could end up providing inappropriate care without meaning to, but they are paralysed by a perceived barrier preventing them from asking questions. This fear about acknowledging difference is likely to stem from a colour-blind approach, where practitioners feel that in order to treat people equally they ought not to 'notice' ethnicity. However, this perspective ignores the experiences of discrimination that a minority client may have faced (Loya, 2011). It also denies the ways that basic needs, such as food and hygiene, are met differently across cultures.

Some of the practitioners could be described as working in a culturally competent way. They were notable for their confidence in how to work across diversity. They were not afraid to ask questions of the client about the relationship between their culture and their care needs. They included relevant cultural and religious needs into the care plan, which all care staff read. They were aware of the need to understand and continually evaluate their own assumptions about culture, and to recognise and respect difference. They understood that clients should not be stereotyped according to their culture. Finally, they understood that they weren't expected to know everything about the client's lifestyle, and they were happy to admit when they did not have knowledge about a client's culture. The key difference between these practitioners and the uncertain practitioners is that the former were open in discussing and asking about diversity. In doing so, they may have relinquished some of the traditional power of the social care practitioner, but they increased their professional competence by ensuring they had the knowledge to work with that client. That is the essence of person-centred care, as one participant noted, and echoes a study of Australian social workers' understandings of what culturally competent work means (Harrison \& Turner, 2011). Perhaps cultural reflexivity rather than competence emerges as a better description for someone who can successfully practice social care with a diversity of clients. Cultural reflexivity implies an 
understanding of one's own ethno-cultural position relative to others, which brings with it a sensitivity to difference. An individual client's own position and needs are then given primacy over any assumed 'cultural' or 'group' norms and expectations, and this can be achieved through personcentred care.

The limitations of the study relate to the nature of qualitative sampling and interviewing. The 39 participants were recruited from three Local Authority regions in the South of England, and therefore their experiences cannot be said to fully represent the experiences of all social care workers in the South of England, or elsewhere. In addition, the theme of how professional competence interacts with diversity emerged spontaneously in some, but not all, of the interviews. It was not a question directly asked in the interview topic guide. The data would have been strengthened if all participants had been asked the same questions about professional competence, yielding the ability to make comparisons between practitioners of different ethnicities. This issue could be addressed in future research.

It is difficult to reconcile the two positions on how diversity training should be delivered. Some of the White British practitioners clearly would like a factfile approach to provide a simple answer to how best to respond to clients from different cultures and religions. However, a practitioner from a minority background argued that such training would be unhelpful because people can't simply be put into boxes and expected to behave in the same way, which is reinforced by the literature $(Y u, 2009)$. The alternative awareness training, emphasising being respectful of difference, which has already been implemented, does not seem to be sufficient because practitioners feel that they still do not have all the knowledge they need. What the present study suggests is that the culturally competent practitioner has a combination of three factors: the confidence to ask questions, sensitivity to difference, and a certain level of knowledge about how cultures differ. If future diversity training can equip social care practitioners with these three factors, while also reminding practitioners that cultures evolve and no one person will embody all of the 
aspects of the culture they belong to, then the workforce will be more confident to work in a culturally competent way. 


\section{References}

Basham, K. (2004). Weaving a tapestry: Anti-racism and the pedagogy of clinical social work practice. Smith College Studies in Social Work, 74, 289-314. doi:10.1080/00377310409517717.

Bowes, A. M. \& Dar, N. S. (2000). Researching social care for minority ethnic older people: Implications of some Scottish research. British Journal of Social Work, 30, 305-321. doi:10.1093/bjsw/30.3.305.

Braun, V. \& Clarke, V. (2006). Using thematic analysis in psychology. Qualitative Research in Psychology, 3, 77-101. doi:10.1191/1478088706qp063oa.

Bryman, A. (2012). Social Research Methods, 4th ed. Oxford: Oxford University Press.

Chand, A. (2005). Do you speak English? Language barriers in child protection social work with minority ethnic families. British Journal of Social Work, 35, 807-821. doi:10.1093/bjsw/bch205.

DH (2001). National Service Framework for Older People. London: The Stationery Office.

Ellins, J. \& Glasby, J. (2016). "You don't know what you are saying 'yes' and what you are saying no' to": Hospital experiences of older people from minority ethnic communities. Ageing \& Society, 36, 42-63. doi:10.1017/S0144686X14000919.

Goldberg, M. (2000). Conflicting principles in multicultural social work. Families in Society, 81, 12-21.

Gunaratnam, Y. (1997). Culture is not enough. In D. Field, J. Hockney \& N. Small (Eds.). Death, Gender and Ethnicity. (pp.166-186). London: Routledge.

Gunaratnam, Y. (2007). Intercultural palliative care: do we need cultural competence? International Journal of Palliative Nursing, 13, 470-7. doi:10.12968/ijpn.2007.13.10.27477.

Harrison, G. \& Turner, R. (2011). Being a 'culturally competent' social worker: Making sense of a murky concept in practice. British Journal of Social Work, 41, 333-350. doi:10.1093/bjsw/bcq101.

HMG (2010). Equality Act. London: The Stationery Office.

HSCIC (2013). Personal Social Services Adult Social Care Survey, England - 2012-13, Final release. Leeds.

Jack, G. \& Gill, O. (2013). Developing cultural competence for social work with families living in poverty. European Journal of Social Work, 16, 220-234. doi:10.1080/13691457.2011.649347.

Johnson, Y. M. \& Munch, S. (2009). Fundamental Contradictions in Cultural Competence. Social Work, 54, 220-231. doi:10.1093/sw/54.3.220

Lievesley, N. (2010). The future ageing of the ethnic minority population of England and Wales. London: Centre for Policy on Ageing and the Runnymede Trust.

Loya, M. (2011). Color-Blind Racial Attitudes in White Social Workers: A Cross-Sectional Study. Smith College Studies in Social Work, 81, 201-217. doi:10.1080/00377317.2011.589341.

Mlcek, S. (2014). Are we doing enough to develop cross-cultural competencies for social work? British Journal of Social Work, 44, 1984-2003. doi:10.1093/bjsw/bct044.

Murphy, K. \& Macleod Clarke, J. (1993). Nurses' experiences of caring for ethnic minority clients. Journal of Advanced Nursing, 18, 442-450. doi:10.1046/j.1365-2648.1993.18030442.x.

Proctor, E. K. \& Davis, L. E. (1994). The challenge of racial difference - Skills for clinical practice. Social Work, 39, 314-323. WOS:A1994NJ40100011.

Richardson, A., Thomas, V. N. \& Richardson, A. (2006). "Reduced to nods and smiles": Experiences of professionals caring for people with cancer from black and ethnic minority groups. European Journal of Oncology Nursing, 10, 93-101. doi:10.1016/j.ejon.2005.05.002.

Staples, L. H. (2000). Insider/outsider upsides and downsides. Social Work with Groups: A Journal of Community and Clinical Practice, 23, 19-35. doi:10.1300/J009v23n02_03.

Thomas, V. \& Dines, A. (1994). The health care needs of ethnic minority groups: Are nurses and individuals playing their part? Journal of Advanced Nursing, 20, 802-808. doi:10.1046/j.13652648.1994.20050802. 
Williams, C. \& Parrott, L. (2013). From Specialism to Genericism: Rising and Falling to the Challenges of Responding to Racial and Ethnic Diversity in Social Work Education in Wales. British Journal of Social Work, 43, 1206-1224. doi:10.1093/bjsw/bcs042.

Williams, C. \& Soydan, H. (2005). When and how does ethnicity matter? A cross-national study of social work responses to ethnicity in child protection cases. British Journal of Social Work, 35, 901-920. doi:10.1093/bjsw/bch281.

Willis, R., Khambhaita, P., Pathak, P. \& Evandrou, M. (2015). Satisfaction with social care services among South Asian and White British older people: The need to understand the system. Ageing \& Society, Online first, 1-24. doi:10.1017/S0144686X15000422.

Yan, M. C. (2008). Exploring Cultural Tensions in Cross-Cultural Social Work Practice. Social Work, 53, 317-328. doi:10.1093/sw/53.4.317

Yu, S. W. K. (2009). The barriers to the effectiveness of culturally sensitive practices in health and social care services for Chinese people in Britain. European Journal of Social Work, 12, 57-70. doi:10.1080/13691450802220982.

\section{About the authors}

Dr Rosalind Willis is an Associate Professor in Gerontology at the Centre for Research on Ageing, University of Southampton, England, where she teaches on the MSc and PhD in Gerontology programmes. Her research interests include care and support in later life, and mental health and ageing, particularly dementia. Much of her research has a focus on ethnic diversity.

Dr Pathik Pathak is a Principal Teaching Fellow in Sociology, Social Policy and Criminology at the University of Southampton, and Faculty Director of Social Enterprise within Social Sciences. He convenes the Sociology module Race and Ethnicity in Society. His research interests include a crosscultural exploration of social entrepreneurship and discourses of employability in global higher education.

Professor Maria Evandrou is Head of the Department of Ageing/Gerontology within Social Sciences at the University of Southampton. Her research interests span three distinct but related areas of investigation: inequalities in later life; informal carers and employment; and the retirement prospects of future generations of elders. A unifying theme throughout much of her research is the use of a dynamic, life course perspective.

Dr Priya Khambhaita is Faculty Research Fellow within Health Sciences at the University of Southampton. Her interest and expertise are centred on the experiences of women, minority ethnic and lower socio-economic groups. She has studied these groups in relation to their access and experiences of social care and health, education and the labour market. Her research is focussed on both the UK and India. 